OPEN ACCESS

Edited by:

Pier Leopoldo Capecchi,

University of Siena, Italy

Reviewed by:

Carlos Egea,

Araba University Hospital, Spain

Nicola Mumoli,

ASST Ovest Milanese, Italy

*Correspondence:

Mingxing Xie

xiemx@hust.edu.cn

Wen-Chih Wu

wen-chih_wu@brown.edu

Philip Haines

philip_haines@brown.edu

Li Zhang

zli429@hust.edu.cn

tThese authors have contributed equally to this work

Specialty section: This article was submitted to General Cardiovascular Medicine, a section of the journal

Frontiers in Cardiovascular Medicine

Received: 23 December 2020 Accepted: 29 March 2021

Published: 28 May 2021

Citation

Sun W, Zhang Y, Wu C, Wang S, Xie Y, Zhang $D$, Yuan $H$, Zhang $Y$, Cui L,

Li M, Zhang Y, Li Y, Wang J, Yang Y,

$L v Q$, Zhang L, Haines P, Wu W-C and Xie M (2021) Early vs. Late Onset

Cardiac Injury and Mortality in Hospitalized COVID-19 Patients in

Wuhan.

Front. Cardiovasc. Med. 8:645587. doi: 10.3389/fcvm.2021.645587

\section{Early vs. Late Onset Cardiac Injury and Mortality in Hospitalized COVID-19 Patients in Wuhan}

\author{
Wei Sun ${ }^{1,2,3 t}$, Yanting Zhang ${ }^{1,2,3 \dagger}$, Chun Wu ${ }^{1,2,3 \dagger}$, Shuyuan Wang ${ }^{1,2,3 \dagger}$, Yuji Xie ${ }^{1,2,3}$, \\ Danqing Zhang 1,2,3, Hongliang Yuan ${ }^{1,2,3}$, Yongxing Zhang ${ }^{1,2,3}$, Li Cui ${ }^{1,2,3}$, Meng $\mathrm{Li}^{1,2,3}$, \\ Yiwei Zhang ${ }^{1,2,3}$, Yuman Li $^{1,2,3}$, Jing Wang ${ }^{1,2,3}$, Yali Yang ${ }^{1,2,3}$, Qing Lv ${ }^{1,2,3}$, Li Zhang ${ }^{1,2,3}$, \\ Philip Haines ${ }^{4 *}$, Wen-Chih $\mathrm{Wu}^{5 *}$ and Mingxing Xie ${ }^{1,2,3 *}$

\begin{abstract}
${ }^{1}$ Department of Ultrasound, Union Hospital, Tongji Medical College, Huazhong University of Science and Technology, Wuhan, China, ${ }^{2}$ Hubei Province Clinical Research Center for Medical Imaging, Wuhan, China, ${ }^{3}$ Hubei Province Key Laboratory of Molecular Imaging, Wuhan, China, ${ }^{4}$ Rhode Island Hospital, Warren Alpert Medical School of Brown University, Providence, RI, United States, ${ }^{5}$ Department of Medicine, Providence VA Medical Center, Brown University Warren Alpert
\end{abstract} \\ Medical School, Providence, Rl, United States
}

Background: Increasing evidence points to cardiac injury $(\mathrm{Cl})$ as a common coronavirus disease 2019 (COVID-19) related complication. The characteristics of early Cl (occurred within $72 \mathrm{~h}$ of admission) and late $\mathrm{Cl}$ (occurred after $72 \mathrm{~h}$ of admission) and its association with mortality in COVID-19 patients is unknown.

Methods: This retrospective study analyzed patients confirmed with COVID-19 in Union Hospital (Wuhan, China) from Jan 29th to Mar 15th, 2020. Clinical outcomes (discharge, or death) were monitored to April 15, 2020, the latest date of follow-up. Demographic, clinical, laboratory, as well as treatment and prognosis were collected and analyzed in patients with early, late $\mathrm{Cl}$ and without $\mathrm{Cl}$.

Results: A total of 196 COVID-19 patients were included for analysis. The median age was 65 years [interquartile range (IQR) 56-73 years], and $112(57.1 \%)$ were male. Of the 196 COVID-19 patients, 49 (25.0\%) patients had early and 20 (10.2\%) patients had late $\mathrm{Cl}, 56.6 \%$ developed Acute-Respiratory-Distress-Syndrome (ARDS) and 43 (21.9\%) patients died. Patients with any $\mathrm{Cl}$ were more likely to have developed ARDS (87.0 vs. $40.2 \%$ ) and had a higher in-hospital mortality than those without (52.2 vs. $5.5 \%, P<0.001)$. Among $\mathrm{Cl}$ subtypes, a significantly higher risk of in-hospital death was found in patients with early $\mathrm{Cl}$ with recurrence [19/49 patients, adjusted odds ratio $(\mathrm{OR})=7.184,95 \% \mathrm{Cl} 1.472-35.071$ ] and patients with late $\mathrm{Cl}$ (adjusted $\mathrm{OR}=5.019$, 95\% Cl 1.125-22.388) compared to patients with early $\mathrm{Cl}$ but no recurrence.

Conclusions: $\mathrm{Cl}$ can occur early on or late after, the initial $72 \mathrm{~h}$ of admission and is associated with ARDS and an increased risk of in-hospital mortality. Both late $\mathrm{Cl}$ and recurrent $\mathrm{Cl}$ after the initial episode were associated with worse outcomes than patients with early $\mathrm{Cl}$ alone. This study highlights the importance of early examination and periodical monitoring of cardiac biomarkers, especially for patients with early $\mathrm{Cl}$ or at risk of clinical deterioration.

Keywords: COVID-19, cardiac injury, early, late, mortality 


\section{INTRODUCTION}

Coronavirus disease 2019 (COVID-19) caused by the severe acute respiratory syndrome coronavirus 2 (SARS-CoV-2) has affected over 200 countries (1). With the increasing number of confirmed cases, the cardiovascular manifestations associated by this highly contagious viral infection have gained more and more attention. Several observational studies have found that between 7.2 and $37.5 \%$ of COVID-19 patients had cardiac injury (CI) which was associated with higher mortality in COVID-19 patients (2-11). However, a portion of CI does not occur on admission and the association of the timing of CI with prognosis is unknown. Furthermore, the clinical features and risk factors associated with early or late onset CI in COVID-19 patients have not been formally evaluated. The clinical sequence preceding and following $\mathrm{CI}$ at the time of admission may provide additional understanding of the pathogenesis associated with CI in COVID19. Therefore, this study compared the clinical characteristics, risk factors and prognostic value of early vs. late onset of CI in COVID-19 patients.

\section{METHODS}

\section{Study Design and Participants}

We performed this retrospective study at Union Hospital (Affiliated Tongji Medical College, Huazhong University of Science and Technology) Wuhan, China. The West Branch of Union Hospital was one of the major designated hospitals for critically ill COVID-19 patients. We enrolled 429 consecutive patients with confirmed COVID-19, according to the WHO interim guidance criteria (12), who were either discharged alive or died during hospitalization from Jan 29th to April 15th, 2020. Only participants who had high-sensitivity troponin I (hsTNI) measured before and after $72 \mathrm{~h}$ from admission during their hospitalization were included in the study (233 patients excluded). The study was approved by the ethics committee of the Union hospital, Tongji Medical College, Huazhong University of Science and Technology. Per institutional policy, written informed consent was waived for all participants with emerging infectious diseases.

\section{Data Collection}

Data were extracted from the electronic medical records including demographic information and clinical characteristics (i.e., vital signs, symptoms, laboratory findings, medical history, underlying comorbidities, treatments, complications, and outcomes) of the participants on admission and during hospitalization. The date of illness onset was defined as the day when symptoms of COVID-19 as defined by the World Health Organization (12) were appreciated. Laboratory measurements within and after $72 \mathrm{~h}$ of admission were collected. If multiple measurements were available, the patient's first abnormal measurements, both within and after $72 \mathrm{~h}$, were recorded for the determination of the timing of the CI. The duration from the onset of admission to the onset of clinical complications and death in the hospital were also recorded. Clinical outcomes (discharge and mortality) were monitored up to April 15, 2020, the last date of follow-up. Complete hospitalization data was available in all patients included in the study.

\section{Timing of $\mathbf{C l}$}

The hs-TNI data for each patient were collected from admission to discharge or death. COVID-19 related CI was defined as the serum levels of cardiac high-sensitivity troponin I (hs-TNI) above the 99th percentile upper reference limit in a patient diagnosed with COVID-19 per Huang et al. and Shi et al. (2, 7-10). Early CI was defined as $\mathrm{CI}$ that occurred within $72 \mathrm{~h}$ of admission, whereas late CI was defined as occurring after $72 \mathrm{~h}$ of admission. We also defined a subgroup of recurrent CI within the early CI group as a second rise of hs-TNI value of $>20 \%$ from its previous value after $72 \mathrm{~h}$ of admission.

\section{Non-cardiac Complications}

Acute respiratory distress syndrome (ARDS) was defined according to the World Health Organization interim guidance criteria (13). Acute kidney injury was identified according to the KDIGO clinical practice guidelines as an increase in serum creatinine by $\geq 0.3 \mathrm{mg} / \mathrm{dl}(\geq 26.5 \mu \mathrm{mol} / \mathrm{l})$ within $48 \mathrm{~h}$ or by 1.5 times of the baseline values (14). Coagulation dysfunction was defined as a $>3$-s prolongation of prothrombin time (PT) or a 5s prolongation of activated partial thromboplastin time (APTT). Thrombocytopenia was characterized by a platelet count $<125 \times$ $10^{9} / \mathrm{L}(15)$.

\section{Statistical Analysis}

Categorical variables were expressed as number (\%), and continuous variables were expressed as mean \pm standard deviation (SD) or median [interquartile range (IQR)]. The normality of the distribution was tested with the ShapiroWilk normality test. Differences among the three groups (without CI, early CI or late CI) were assessed by ANOVA for normally distributed and Kruskal-Wallis $H$-test for nonnormally distributed continuous variables. Categorical variables were compared by Chi-square or Fisher exact test where applicable. In-hospital survival curves of four groups of patients with early but no recurrent CI, early with recurrent CI, late $\mathrm{CI}$, and no CI were estimated with the Kaplan-Meier method and the groups compared with the log-rank test. Univariate and multivariate logistic regression analyses were used to determine the independent risk associated with each of the four groups (early but no recurrent CI, early with recurrent CI, late CI, and no CI) of patients with in-hospital death, adjusted by known risk factors of COVID-19 mortality in the literature [age, sex, respiratory rate, heart rate, $\mathrm{SpO}_{2}$, temperature, mean arterial pressure, coma, hypertension history, Lymphocyte count, Creactive protein (CRP), and lactate dehydrogenase (LDH)] (1618). All statistical analyses were performed with SPSS version 24.0 (Statistical Package for the Social Sciences, Chicago, Illinois), and STATA software version 10 (StataCorp, Texas, USA). A twotailed $P$-value of $<0.05$ was considered statistically significant. 


\section{RESULTS}

\section{Clinical Characteristics, Laboratory Findings, and Treatments Within $72 \mathrm{~h}$ of Admission}

Among the 429 patients, 100 patients were excluded due to missing hs-TNI data during the entire hospitalization, 133 patients were excluded due to missing hs-TNI data within $72 \mathrm{~h}$ of admission, the remaining 196 patients were included for analysis. The median age was 65.0 years (IQR: $56.0-73.0$ years), and 112 (57.1\%) were men. Of 196 COVID-19 patients, 69/196 (35.2\%) had evidence of CI during hospitalization: 49/196 (25.0\%) patients had early CI and 20/196 (10.2\%) patients had late CI. In addition, 19/49 (38.8\%) patients with early CI had recurrent $\mathrm{CI}$ after $72 \mathrm{~h}$ of admission. Compared with patients without CI, patients with early and late CI were more often older, and had lower $\mathrm{SpO}_{2}$ on admission. They also had more comorbidities such as hypertension and underlying cardiac disease.

Compared with non-CI group, patients with early and late CI presented with more abnormal laboratory findings within $72 \mathrm{~h}$ of admission including lower lymphocyte and platelet counts, higher inflammation-related indices [CRP, procalcitonin (PCT)] and further elevations in liver and renal function indices.

Concerning the treatment of the 196 patients within $72 \mathrm{~h}$ of admission, there was no difference in the antiviral $(P=$ $0.551)$ or antibiotic therapy $(P=0.235)$ among these three groups. However, compared with the non-CI group, more patients with early and late CI received glucocorticoid therapy (18.9 vs. $38.8 \%$ and $30.0 \%, P=0.021$ ), high-flow oxygen ( 18.1 vs. $69.4 \%$ and $80.0 \%, P<0.001$ ), invasive mechanical ventilation ( 0.8 vs. $4.1 \%$ and $15.0 \% ; P=0.005)$, noninvasive mechanical ventilation $(0.0$ vs. $8.2 \%$ and $15.0 \% ; P$ $<0.001$ ), and more subjects were transferred to the intensive care unit (ICU) $(0.8$ vs. $10.2 \%$ and $5.0 \% ; P=0.007)$ (Table 1).

\section{Timing of $\mathrm{Cl}$ and Non-cardiac Complications After $\mathbf{7 2} \mathrm{h}$ of Admission}

Major complications after $72 \mathrm{~h}$ included ARDS [111/196 (56.6\%)], coagulation dysfunction [57/193 (29.5\%)], late CI [20/196 (10.2\%)] and acute kidney injury [33/193 (17.1\%)]. Patients with early and late CI were more likely to have developed ARDS, ICU transfer and receive invasive mechanical ventilation (IMV) during their hospitalization compared to the non-CI group (Table 2). A majority, 87.0\% (60/69) of patients with CI vs. $40.2 \%(51 / 127)$ without CI, developed ARDS. Overall, the median time from admission to ARDS was 4 days, to acute kidney injury was 7 days, to late CI was 11 days, and to coagulation dysfunction was 11 days for all patients.

For the early CI group $(n=49)$, the median time from admission to CI was 1 day (IQR 0-1 day), to the onset of ARDS (81.6\%) was 2 days (IQR 1-8 days), and to the onset of recurrent CI $[19 / 49(38.8 \%)]$ was 7 days (IQR 5-16 days) for affected patients (Figure 1A). For the late CI group [20/196 (10.2\%)], the median time from admission to the onset of ARDS (100\%) was 7 days (IQR 2-8 days) and the onset of late CI was 11 days (IQR 522 days) (Figure 1B). Conversely, for the non-CI group [127/196 $(64.8 \%)]$, the median time from admission to the onset of ARDS (40.2\%) was 6 days (IQR 3-12 days) (Figure 1C).

Using the onset of ARDS as the temporal reference point, $15 / 20(75 \%)$ patients with late CI had ARDS before their CI (Figure 2), with a median time between ARDS and CI of 4 days (IQR 3-17 days).

\section{Cardiac Injury and Mortality}

As of April 15, 2020, 153 patients (78.1\%) were discharged and 43 patients $(21.9 \%)$ died in the hospital. Patients with any CI had significantly higher in-hospital mortality than those without (52.2 vs. 5.5\%, $P<0.001$ ) (Figure 3). Among CI subtypes, multivariable regression modeling showed that compared to patients with early CI but no recurrence, a significantly higher risk of in-hospital death was found in patients with early CI with recurrence [odds ratio $(\mathrm{OR})=7.184, P$ $=0.015]$ and patients with late $\mathrm{CI}(\mathrm{OR}=5.019, P=0.034)$ (Table 3).

\section{DISCUSSION}

In this cohort of 196 hospitalized COVID-19 patients from Wuhan, China, we found $35.2 \%$ had evidence of CI during hospitalization that included $25.0 \%$ of patients with early CI and $10.2 \%$ patients with late CI. In addition, there were $38.8 \%$ of patients with early CI who also had recurrent CI. Patients with any CI had significantly higher incidence of ARDS and in-hospital mortality than those without. Moreover, among CI subtypes, a significantly higher risk of in-hospital death was found in patients with early CI with recurrence and patients with late CI compared to patients with early CI and no recurrence.

Increasingly, researchers are reporting CI in COVID-19 patients, with the prevalence varying from 7.2 to $37.5 \%(4,7$, $8,11)$. In our study, a remarkable $35.2 \%$ of patients had any CI. The pathogenesis of CI associated with COVID-19 is still unknown partly due to a dearth of autopsy or biopsy reported in these patients. The following potential mechanisms for CI have been proposed. The first possibility is direct myocardial damage by the virus, because angiotensin-converting enzyme 2 has been identified as a functional receptor for coronaviruses, which is also expressed abundantly in the myocardium (19, 20). Mixed literature from autopsy and biopsy case series were reported without conclusive evidence yet (21-25). The second mechanism is presumably the systemic inflammatory cytokine response, namely cytokine storm $(26,27)$. It can cause the proliferation of highly pro-inflammatory CCR4+CCR6+Th17 cells amongst the CD4+T cells, the expression of high concentrations of cytotoxic particles in CD8+ $\mathrm{T}$ cells and over activation of $\mathrm{T}$ cells in general, all of which lead to a stronger inflammatory response in return $(3,21)$. Inflammation can in turn lead to thromboembolic complications (28). Our study showed that inflammation-related indices (CRP, PCT) were higher 
TABLE 1 | Comparisons of demographics, clinical characteristics and laboratory examinations on admission within $72 \mathrm{~h}$ among the three groups.

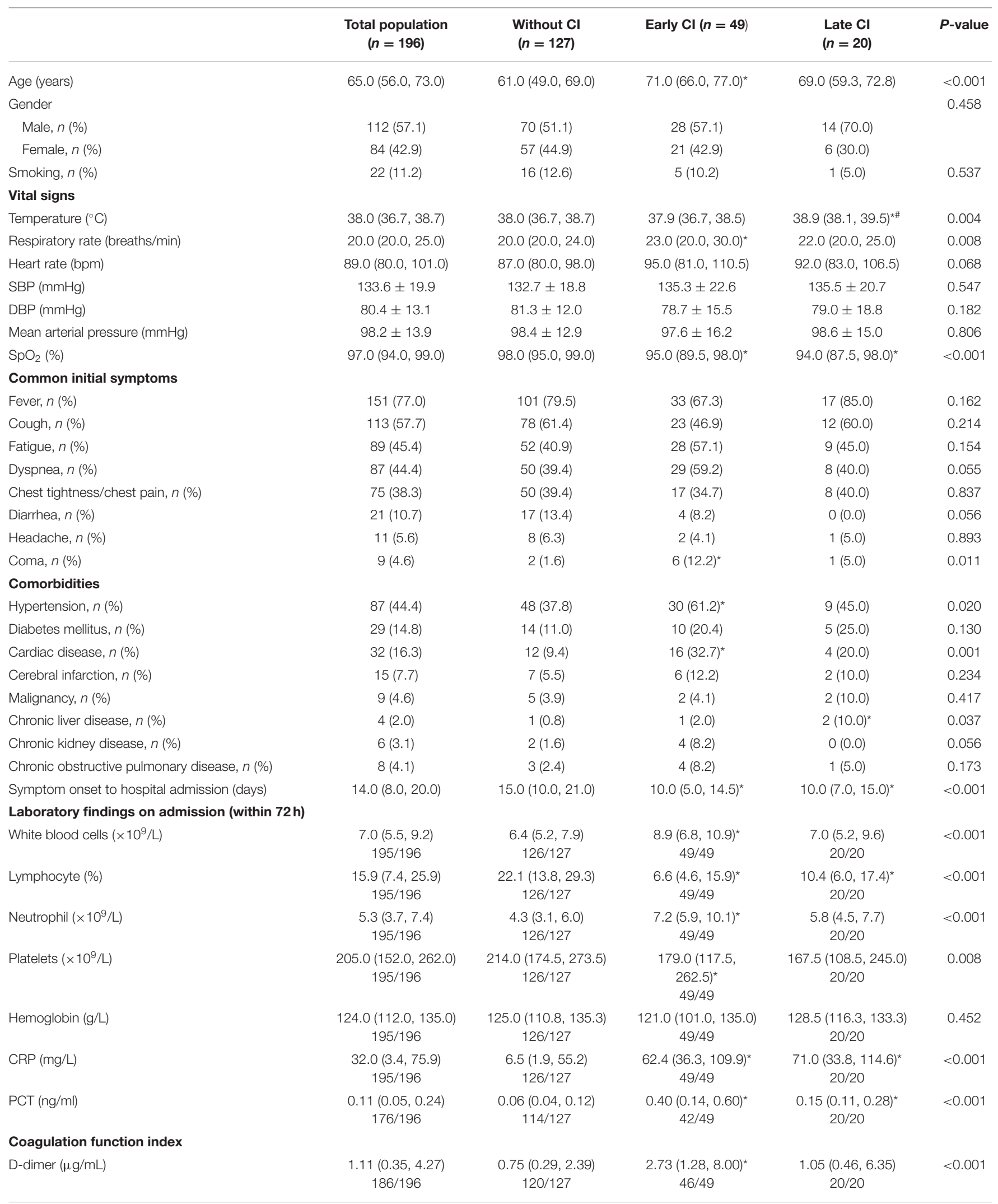


TABLE 1 | Continued

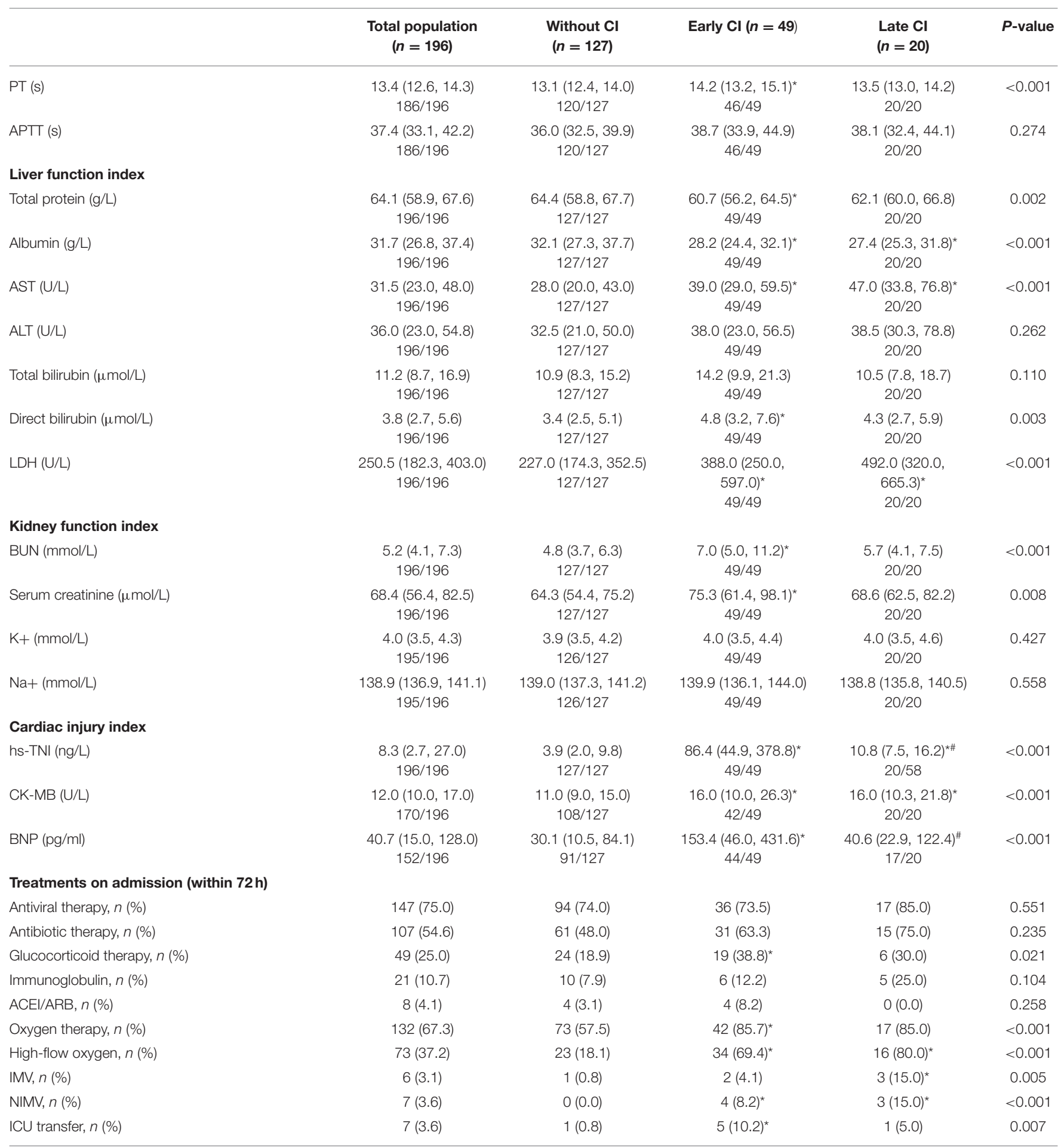

${ }^{\star} P<0.05$, vs. without Cl; ${ }^{\#} P<0.05$, vs. early Cl; ACE-I, angiotensin-converting enzyme inhibitors; ALT, alanine aminotransferase; APTT, activated partial thromboplastin time; ARB, angiotensin II receptor blockers; AST, aspartate aminotransferase; BNP, B-type natriuretic peptide; BUN, blood urea nitrogen; Cl, cardiac injury; CK-MB, creatine kinase muscle-brain; CRP, C-reactive protein; DBP, diastolic blood pressure; hs-TNI, hypersensitive troponin I; ICU, intensive care unit; IMV, invasive mechanical ventilation; IQR, interquartile range; LDH, lactate dehydrogenase; NIMV, non-invasive mechanical ventilation; PCT, procalcitonin; PT, prothrombin time; SBP, systolic blood pressure; SD, standard deviation.

in the CI group compared to the non-CI group. Another mechanism is CI related to hypoxia. The balance between the oxygen demand and supply of the myocardium is disrupted during acute hypoxia. A cascade of cellular, biochemical and inflammatory reactions can occur during hypoxia, eventually causing myocardial apoptosis (29). Acute severe hypoxia can 
TABLE 2 | Comparisons of additional treatment, complications, and prognosis after $72 \mathrm{~h}$ of admission among the three groups.

\begin{tabular}{|c|c|c|c|c|c|}
\hline Variables & $\begin{array}{l}\text { Total population } \\
\qquad(n=196)\end{array}$ & $\begin{array}{l}\text { Without Cl } \\
(n=127)\end{array}$ & $\begin{array}{l}\text { Early Cl } \\
(n=49)\end{array}$ & $\begin{array}{l}\text { Late Cl } \\
(n=20)\end{array}$ & $P$-value \\
\hline \multicolumn{6}{|c|}{ Additional treatment after admission } \\
\hline Antiviral therapy, $n(\%)$ & $36(18.4)$ & $24(18.9)$ & $9(18.4)$ & $3(15.0)$ & 1.000 \\
\hline Antibiotic therapy, $n(\%)$ & $50(25.5)$ & $31(24.4)$ & $14(28.6)$ & $5(25.0)$ & 0.882 \\
\hline Glucocorticoid therapy, $n$ (\%) & $48(24.5)$ & $26(20.5)$ & $11(22.4)$ & $11(55.0)^{\star \#}$ & 0.007 \\
\hline Oxygen therapy, $n(\%)$ & $34(17.3)$ & $26(20.5)$ & $5(10.2)$ & $3(15.0)$ & 0.273 \\
\hline High-flow oxygen, $n(\%)$ & $51(26.0)$ & $42(33.1)$ & $5(10.2)^{*}$ & $4(20.0)$ & 0.006 \\
\hline IMV, $n(\%)$ & $33(16.8)$ & $8(6.3)$ & $13(26.5)^{\star}$ & $12(60.0)^{\star \#}$ & $<0.001$ \\
\hline NIMV, $n(\%)$ & $16(8.2)$ & $8(6.3)$ & $5(10.2)$ & $3(15.0)$ & 0.234 \\
\hline ICU transfer, $n(\%)$ & $25(12.8)$ & $6(4.7)$ & $7(14.3)$ & $12(60.0)^{\star \#}$ & $<0.001$ \\
\hline Recurrent $\mathrm{Cl}, n(\%)$ & $19 / 49(38.8)$ & / & 19/49 (38.8) & / & / \\
\hline Late $\mathrm{Cl}, n(\%)$ & 20/196 (10.2) & / & / & 20/20 (100) & / \\
\hline ARDS, $n(\%)$ & 111/196 (56.6) & $51 / 127(40.2)$ & $40 / 49(81.6)^{*}$ & $20 / 20(100)^{\star}$ & $<0.001$ \\
\hline Coagulation dysfunction, $n$ (\%) & $57 / 193(29.5)$ & 21/124 (16.9) & $22 / 49(44.9)^{*}$ & $14 / 20(70.0)^{\star}$ & $<0.001$ \\
\hline Acute kidney injury, $n$ (\%) & 33/193 (17.1) & $8 / 125(6.4)$ & $17 / 48(35.4)^{*}$ & $8 / 20(40.0)^{*}$ & $<0.001$ \\
\hline \multicolumn{6}{|c|}{ Time from admission to complications onset } \\
\hline \multicolumn{6}{|l|}{ Cardiac injury (Cl) } \\
\hline Early Cl (days) & $1(0,1)$ & I & $1(0,1)$ & / & / \\
\hline Recurrent Cl (days) & $7(5,16)$ & / & $7(5,16)$ & / & / \\
\hline Late $\mathrm{Cl}$ (days) & $11(5,22)$ & / & / & $11(5,22)$ & / \\
\hline ARDS (days) & $4(2,9)$ & $6(3,12)$ & $2(1,8)^{\star}$ & $7(2,8)$ & 0.014 \\
\hline
\end{tabular}

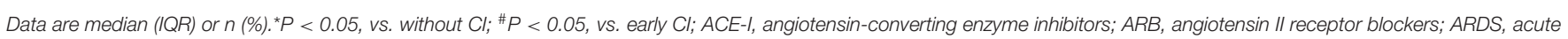
respiratory distress syndrome; ICU, intensive care unit; IMV, invasive mechanical ventilation; IQR, interquartile range; NIMV, non-invasive mechanical ventilation.

also trigger a systemic inflammatory response (30). In this study, patients with early or late $\mathrm{CI}$ had lower level of $\mathrm{SpO}_{2}$ on admission and higher incidence of ARDS compared to the non-CI group. There was a large timing overlap between $\mathrm{CI}$ and ARDS in the early CI group and $75 \%$ of patients with late CI were preceded by ARDS which supports a strong relationship between CI and hypoxia. Lastly, antiviral drugs can cause cardiac insufficiency, arrhythmia or other cardiovascular disorders with variable individual susceptibility $(4,31)$. In the present study, almost all patients (93.4\% of COVID-19 patients) were administrated with antiviral drugs either on admission or after admission for which the opportunity of individual susceptibility and/or interaction with the underlying comorbid conditions could contribute to onset of late $\mathrm{CI}$ or recurrence of the initial one. In addition, patients in the CI group were more likely to have received glucocorticoid therapy. The relationship between glucocorticoid therapy and cardiac injury remains controversial and is under investigation (32). On the other hand, it is also likely that patients with any CI had higher disease severity for which more treatment was administered. This may suggest that the CI after admission was a sign of disease severity and/or progression.

Recent studies have demonstrated that CI was associated with increased mortality in COVID-19 patients $(7,8,33)$. However, to the best of our knowledge, this is the first study to depict the clinical characteristics of both early $\mathrm{CI}$ and late $\mathrm{CI}$ and their association with in-hospital mortality. Our study showed that early CI was an independent predictor of death in COVID-19 patients even after accounting for variables that have proven prognostic value in the risk stratification of acutely ill patients, such as respiratory rate, heart rate, $\mathrm{SpO}_{2}$, temperature, mean arterial pressure, and coma $(16,34)$. Cardiac injury remained significant after accounting for potential confounding laboratory variables with proven prognostic value in COVID hospitalizations such as lymphocyte count, LDH, CRP (17). This is important because clinicians should not consider patients 

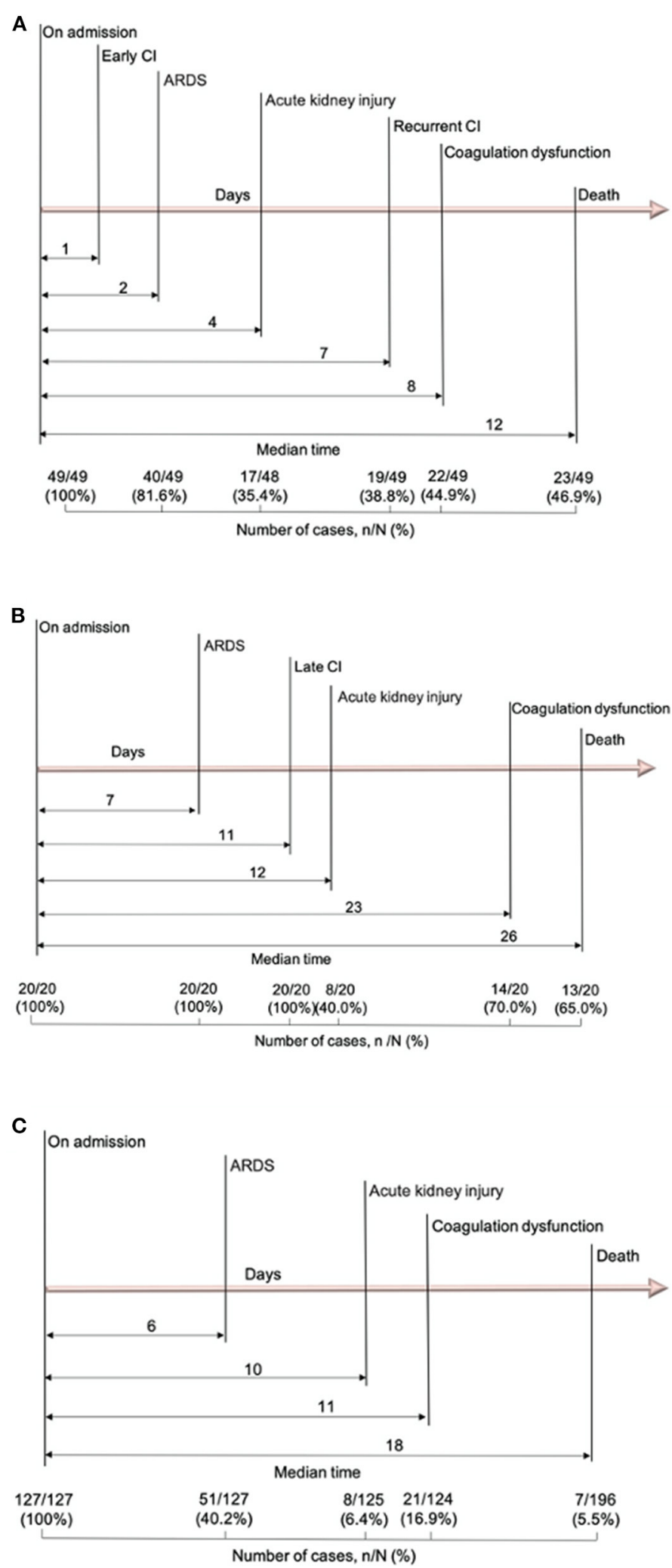

FIGURE 1 | Timeline of COVID-19 patients after admission. (A) Timeline of COVID-19 patients with early Cl; (B) Timeline of COVID-19 patients with late Cl; (C) Timeline of COVID-19 patients without Cl. COVID-19, coronavirus disease 2019; Cl, cardiac injury. 


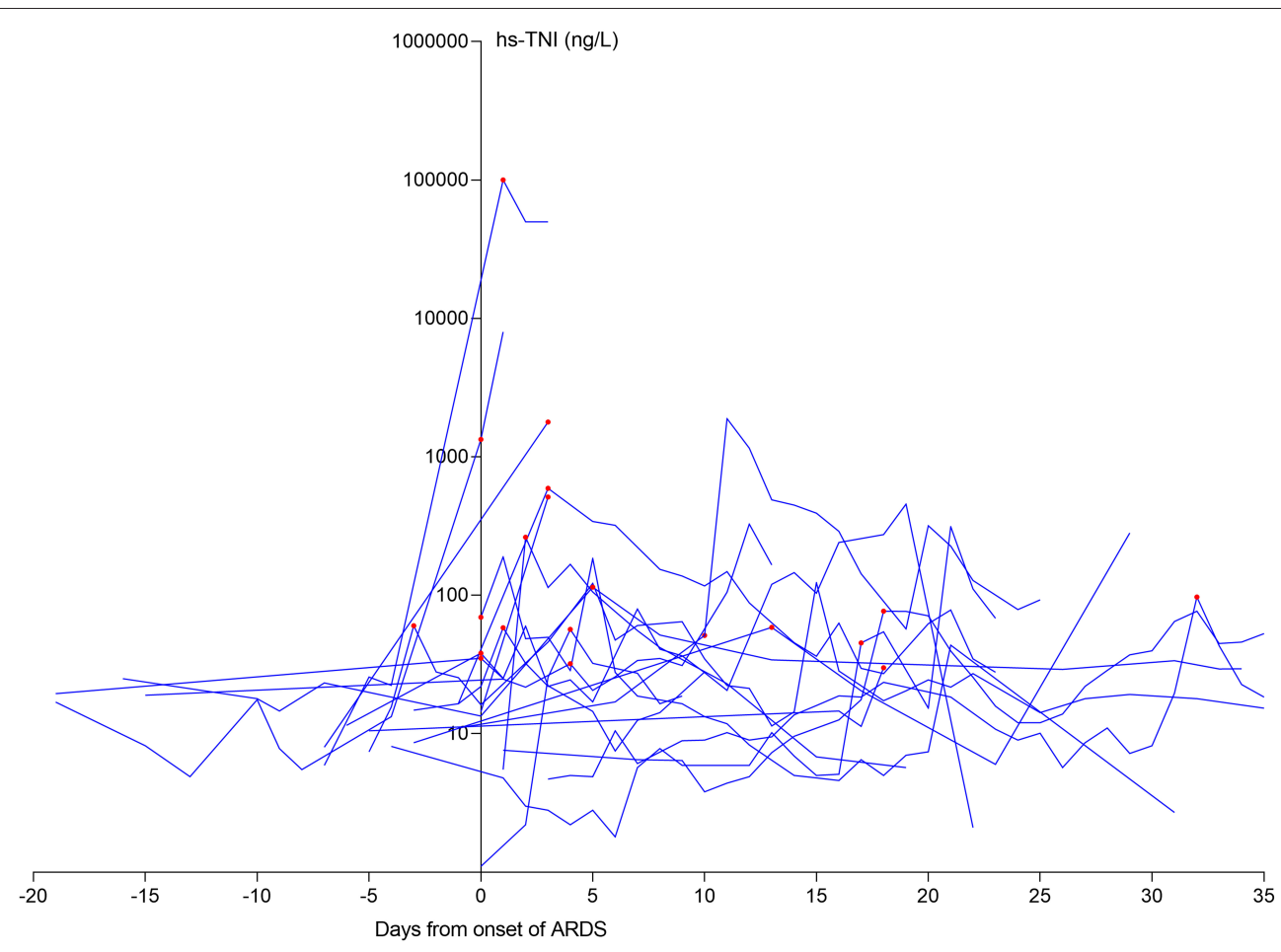

FIGURE 2 | The dynamic profile of hs-TNI levels in late Cl patients in relation to ARDS onset. 15/20 (75.0\%) patients suffering from late Cl after the onset of ARDS. The levels of hs-TN were log transformed. ARDS, acute respiratory distress syndrome; Cl, cardiac injury; hs-TNI, high-sensitivity troponin I.

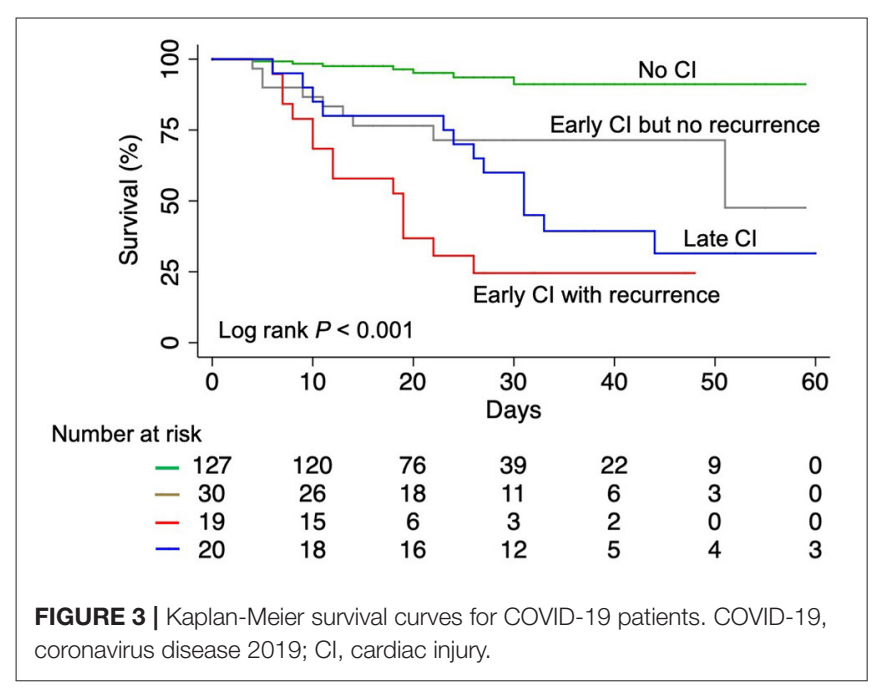

being out of danger despite absence of $\mathrm{CI}$ in the first $72 \mathrm{~h}$ since it can occur late. Similarly, a fall after the early rise in Trop I should not translate into a lower risk status since recurrence of CI can occur. Conversely, we also found that CI is closely related to the occurrence of ARDS as opposed to a primary cardiac event. Accordingly, our study suggested the need for a more systematic assessment of cardiac troponins for risk stratification of COVID-19 patients on admission, with repeat measures for those who already have initial CI or who are at risk for clinical deterioration. With the advent of multiple therapies now to reduce the morbidity and mortality of COVID-19 (3537), early identification of higher risk patients with cardiac biomarkers may be helpful to balance the cost vs. the effect of therapy.

\section{LIMITATIONS}

Our study has some limitations. First, this was a relatively small sample size and single-center retrospective observational study for which residual confounding cannot be excluded and we did not include all the potential factors associated with mortality in our study. Second, only 196 patients both had the data of hs-TNI within and after $72 \mathrm{~h}$ of admission, which may have underestimated the true incidence of CI in our study. Therefore, future studies should be multi-centered, with larger sample size and systematic data collection, in order to promote a more comprehensive understanding of the association between cardiac injury and mortality in hospitalized patients with COVID-19.

\section{CONCLUSIONS}

$\mathrm{CI}$ is a common condition that can occur early on or late after, the initial $72 \mathrm{~h}$ of admission and is associated with ARDS and an increased risk of in-hospital mortality. Both late CI 
TABLE 3 | Univariate and multivariate logistic regression analysis of factors associated with in-hospital mortality of COVID-19 patients.

\begin{tabular}{|c|c|c|c|c|}
\hline \multirow[b]{2}{*}{ Factors } & \multicolumn{2}{|c|}{ Univariate } & \multicolumn{2}{|c|}{ Multivariate } \\
\hline & $\begin{array}{c}\text { Unadjusted OR } \\
\text { (95\% confidence interval) }\end{array}$ & $P$-value & $\begin{array}{c}\text { Adjusted OR } \\
\text { (95\% confidence interval) }\end{array}$ & $P$-value \\
\hline \multicolumn{5}{|l|}{ Age group (years) } \\
\hline$<45$ & 1 (ref) & & & \\
\hline $45-54$ & $0.680(0.040,11.632)$ & 0.79 & & \\
\hline $55-64$ & $4.675(0.559,39.116)$ & 0.155 & & \\
\hline $65-74$ & $7.650(0.944,61.980)$ & 0.057 & & \\
\hline$>74$ & $6.581(0.787,55.045)$ & 0.082 & & \\
\hline \multicolumn{5}{|l|}{ Sex } \\
\hline Female & 1 (ref) & & 1 (ref) & \\
\hline Male & $3.632(1.632,8.086)$ & 0.002 & $8.828(2.463,31.643)$ & 0.001 \\
\hline \multicolumn{5}{|l|}{ Respiratory rate (breaths/min) } \\
\hline $12-24$ & 1 (ref) & & 1 (ref) & \\
\hline$>24$ & $3.667(1.804,7.451)$ & $<0.001$ & $3.773(1.188,11.983)$ & 0.024 \\
\hline \multicolumn{5}{|l|}{ Heart rate (bpm) } \\
\hline $70-109$ & 1 (ref) & & & \\
\hline $40-69$ & $2.321(0.547,9.845)$ & 0.253 & & \\
\hline $110-139$ & $3.095(1.261,7.600)$ & 0.014 & & \\
\hline $140-179$ & $4.643(0.627,34.377)$ & 0.133 & & \\
\hline \multicolumn{5}{|l|}{$\mathrm{SpO}_{2}(\%)$} \\
\hline$>89$ & 1 (ref) & & 1 (ref) & \\
\hline$<75$ & $24.833(2.661,231.712)$ & 0.005 & $8.264(0.694,98.332)$ & 0.095 \\
\hline $75-85$ & $31.042(6.405,150.435)$ & $<0.001$ & $11.129(1.341,92.388)$ & 0.026 \\
\hline $86-89$ & $31.042(3.474,277.332)$ & 0.002 & $74.421(3.121,1774.444)$ & 0.008 \\
\hline \multicolumn{5}{|l|}{ Temperature $\left({ }^{\circ} \mathrm{C}\right)$} \\
\hline$<37.2$ & 1 (ref) & & & \\
\hline $37.2-38.9$ & $1.991(0.855,4.633)$ & 0.11 & & \\
\hline$>38.9$ & $2.031(0.741,5.564)$ & 0.168 & & \\
\hline \multicolumn{5}{|l|}{ Mean arterial pressure (mmHg) } \\
\hline $70-109$ & 1 (ref) & & & \\
\hline $50-69$ & $8.065(0.708,91.829)$ & 0.094 & & \\
\hline $110-129$ & $1.578(0.664,3.748)$ & 0.302 & & \\
\hline $130-159$ & $1.008(0.109,9.340)$ & 0.994 & & \\
\hline Coma (yes vs. no) (9 vs. 320) & $8.108(1.937,33.944)$ & 0.004 & & \\
\hline Hypertension (yes vs. no) (139 vs. 190) & $2.974(1.467,6.029)$ & 0.003 & & \\
\hline \multicolumn{5}{|l|}{ Lymphocytes (\%) } \\
\hline$\geq 20$ & 1 (ref) & & & \\
\hline$<20$ & 10.551 (3.594, 30.980) & $<0.001$ & & \\
\hline \multicolumn{5}{|l|}{ CRP (mg/L) } \\
\hline$\leq 8$ & 1 (ref) & & & \\
\hline$>8$ & $17.500(4.086,74.956)$ & $<0.001$ & & \\
\hline \multicolumn{5}{|l|}{ LDH (U/L) } \\
\hline$\leq 245$ & 1 (ref) & & & \\
\hline$>245$ & $8.129(3.239,20.398)$ & $<0.001$ & & \\
\hline \multicolumn{5}{|l|}{ Type of $\mathrm{Cl}$} \\
\hline Early $\mathrm{Cl}$ but no recurrence & 1 (ref) & & 1 (ref) & \\
\hline Early $\mathrm{Cl}$ with recurrence & $6.533(1.807,23.627)$ & 0.004 & $7.184(1.472,35.071)$ & 0.015 \\
\hline Late $\mathrm{Cl}$ & $4.333(1.298,14.471)$ & 0.017 & $5.019(1.125,22.388)$ & 0.034 \\
\hline $\mathrm{No} \mathrm{Cl}$ & $0.136(0.046,0.405)$ & $<0.001$ & $0.119(0.030,0.475)$ & 0.003 \\
\hline
\end{tabular}

OR, odds ratio; Cl, cardiac injury; COVID-19, coronavirus disease 2019; CRP, C-reactive protein; LDH, lactate dehydrogenase. 
and recurrent $\mathrm{CI}$ after the initial episode were associated with worse outcomes than patients with early CI alone. This study highlights the importance of early examination and periodical monitoring of cardiac biomarkers to identify predictors and markers of clinical deterioration in COVID-19 patients to guide intervention.

\section{DATA AVAILABILITY STATEMENT}

The original contributions presented in the study are included in the article/supplementary material, further inquiries can be directed to the corresponding authors.

\section{ETHICS STATEMENT}

The studies involving human participants were reviewed and approved by the Ethics Committee of Tongji Medical College, Huazhong University of Science and Technology. Written informed consent was waived for all participants with emerging infectious diseases. Written informed consent for participation was not required for this study in accordance with the national legislation and the institutional requirements.

\section{REFERENCES}

1. World Health Organization. Novel Coronavirus (2019-nCoV): Situation Report-88. Available online at: https://www.who.int/docs/defaultsource/coronaviruse/situation-reports/20200417-sitrep-88-covid191b6cccd94f8b4f219377bff55719a6ed.pdf (accessed December 22, 2020).

2. Huang C, Wang Y, Li X, Ren L, Zhao J, Hu Y, et al. Clinical features of patients infected with 2019 novel coronavirus in Wuhan, China. Lancet. (2020) 395:497-506. doi: 10.1016/S0140-6736(20)30183-5

3. Guan WJ, Ni ZY, Hu Y, Liang WH, Ou CQ, He JX, et al. Clinical characteristics of coronavirus disease 2019 in China. N Engl J Med. (2020) 382:170820. doi: 10.1056/NEJMoa2002032

4. Wang D, Hu B, Hu C, Zhu F, Liu X, Zhang J, et al. Clinical characteristics of 138 hospitalized patients with 2019 novel coronavirus-infected pneumonia in Wuhan, China. JAMA. (2020) 323:1061-9. doi: 10.1001/jama.2020.1585

5. Zhou F, Yu T, Du R, Fan G, Liu Y, Liu Z, et al. Clinical course and risk factors for mortality of adult inpatients with COVID-19 in Wuhan, China: a retrospective cohort study. Lancet. (2020) 395:105462. doi: 10.1016/S0140-6736(20)30566-3

6. Yang X, Yu Y, Xu J, Shu H, Xia J, Liu H, et al. Clinical course and outcomes of critically ill patients with SARS-CoV-2 pneumonia in Wuhan, China: a single-centered, retrospective, observational study. Lancet Respir Med. (2020) 8:475-81. doi: 10.1016/S2213-2600(20)30079-5

7. Shi S, Qin M, Shen B, Cai Y, Liu T, Yang F, et al. Association of cardiac injury with mortality in hospitalized patients with COVID-19 in Wuhan, China. JAMA Cardiol. (2020) 5:802-10. doi: 10.1001/jamacardio.2020.0950

8. Guo T, Fan Y, Chen M, Wu X, Zhang L, He T, et al. Cardiovascular implications of fatal outcomes of patients with coronavirus disease 2019 (COVID-19). JAMA Cardiol. (2020) 5:811-8. doi: 10.1001/jamacardio.2020.1017

9. Shi S, Qin M, Cai Y, Liu T, Shen B, Yang F, et al. Characteristics and clinical significance of myocardial injury in patients with severe coronavirus disease 2019. Eur Heart J. (2020) 41:2070-9. doi: 10.1093/eurheartj/ ehaa 408

10. Ferrante G, Fazzari F, Cozzi O, Maurina M, Bragato R, D’Orazio F, et al. Risk factors for myocardial injury and death in patients with COVID-19: insights from a cohort study with chest computed tomography. Cardiovasc Res. (2020) 116:2239-46. doi: 10.1093/cvr/cvaa193

\section{AUTHOR CONTRIBUTIONS}

MX, W-CW, PH, and LZ: conception and design of study. WS, YaZ, CW, SW, DZ, HY, YoZ, LC, YL, JW, YY, and QL: acquisition of data. YaZ, WS, SW, ML, and YiZ: analysis and/or interpretation of data. LZ, WS, YaZ, and $\mathrm{CW}$ : drafting the manuscript. MX, W-CW, PH, and LZ: revising the manuscript critically for important intellectual content. All authors contributed to the article and approved the submitted version.

\section{FUNDING}

This work was supported by the National Natural Science Foundation of China (Grant No. 81922033 to LZ; Grant No. 81727805 to $\mathrm{MX})$.

\section{ACKNOWLEDGMENTS}

The authors would like to express their appreciation for all of the emergency services, nurses, doctors, and other hospital staff for their efforts to combat the COVID-19 outbreak.

11. Deng Q, Hu B, Zhang Y, Wang H, Zhou X, Hu W, et al. Suspected myocardial injury in patients with COVID-19: evidence from front-line clinical observation in Wuhan, China. Int J Cardiol. (2020) 311:11621. doi: $10.1016 /$ j.ijcard.2020.03.087

12. World Health Organization. Clinical Management of Severe Acute Respiratory Infection When Novel Coronavirus ( $n \mathrm{CoV}$ ) Infection Is Suspected: Interim Guidance, 25 January 2020. World Health Organization (2020). Available online at: https://apps.who.int/iris/handle/10665/330854 (accessed December 22, 2020).

13. World Health Organization. COVID-19 Clinical Management: Living Guidance (2020). Available online at: https://www.who.int/publications/i/ item/WHO-2019-nCoV-clinical-2021-1 (accessed February 12, 2021).

14. Kidney Disease Improving Global Outcomes. Acute Kidney Injury Work Group: KDIGO clinical practice guideline for acute kidney injury. Kidney Int. (2012) 2:1-138. doi: 10.1038/kisup.2012.1

15. World Health Organization. Nutritional Anaemias. Report of a WHO Scientific Group. World Health Organization technical report series no. 405. Geneva: World Health Organization (1968). p. 5-37.

16. $\mathrm{Hu} \mathrm{H}$, Yao N, Qiu Y. Comparing rapid scoring systems in mortality prediction of critically ill patients with novel coronavirus disease. Acad Emerg Med. (2020) 27:461-8. doi: 10.1111/acem.13992

17. Yan L, Zhang H, Goncalves J, Xiao Y, Wang M, Guo Y, et al. An interpretable mortality prediction model for COVID-19 patients. Nat Mach Intell. (2020) 2:283-8. doi: 10.1038/s42256-020-0180-7

18. Shi Y, Yu X, Zhao H, Wang H, Zhao R, Sheng J. Host susceptibility to severe COVID-19 and establishment of a host risk score: findings of 487 cases outside Wuhan. Crit Care. (2020) 24:108. doi: 10.1186/s13054-0202833-7

19. Turner AJ, Hiscox JA, Hooper NM. ACE2: from vasopeptidase to SARS virus receptor. Trends Pharmacol Sci. (2004) 25:2914. doi: 10.1016/j.tips.2004.04.001

20. Gallagher PE, Ferrario CM, Tallant EA. Regulation of ACE2 in cardiac myocytes and fibroblasts. Am J Physiol Heart Circ Physiol. (2008) 295:H23739. doi: 10.1152/ajpheart.00426.2008

21. Xu Z, Shi L, Wang Y, Zhang J, Huang L, Zhang C, et al. Pathological findings of COVID-19 associated with acute respiratory distress syndrome. Lancet Respir Med. (2020) 8:420-2. doi: 10.1016/S2213-2600(20)3 0076-X 
22. Tavazzi G, Pellegrini C, Maurelli M, Belliato M, Sciutti F, Bottazzi A, et al. Myocardial localization of coronavirus in COVID-19 cardiogenic shock. Eur J Heart Fail. (2020) 22:911-5. doi: 10.1002/ejhf.1828

23. Wichmann D, Sperhake JP, Lütgehetmann M, Steurer S, Edler C, Heinemann A, et al. Autopsy findings and venous thromboembolism in patients with COVID-19: a prospective cohort Study. Ann Intern Med. (2020) 173:26877. doi: 10.7326/L20-1206

24. Lindner D, Fitzek A, Bräuninger H, Aleshcheva G, Edler C, Meissner K, et al. Association of cardiac infection with SARS-CoV2 in confirmed COVID-19 autopsy cases. JAMA Cardiol. (2020) 5:1281-5. doi: 10.1001/jamacardio.2020.3551

25. Schaller T, Hirschbühl K, Burkhardt K, Braun G, Trepel M, Märkl B, et al. Postmortem examination of patients with COVID-19. JAMA. (2020) 323:2518-20. doi: 10.1001/jama.2020.8907

26. Tang Y, Liu J, Zhang D, Xu Z, Ji J, Wen C. Cytokine storm in COVID19: the current evidence and treatment strategies. Front Immunol. (2020) 11:1708. doi: 10.3389/fimmu.2020.01708

27. Mahmudpour M, Roozbeh J, Keshavarz M, Farrokhi S, Nabipour I. COVID-19 cytokine storm: the anger of inflammation. Cytokine. (2020) 133:155151. doi: 10.1016/j.cyto.2020.155151

28. Zhang L, Feng X, Zhang D, Jiang C, Mei H, Wang J, et al. Deep vein thrombosis in hospitalized patients with COVID-19 in Wuhan, China: prevalence, risk factors, and outcome. Circulation. (2020) 142:11428. doi: 10.1161/CIR.0000000000000887

29. Han Q, Li G, Ip MS, Zhang Y, Zhen Z, Mak JC, et al. Haemin attenuates intermittent hypoxia-induced cardiac injury via inhibiting mitochondrial fission. J Cell Mol Med. (2018) 22:2717-26. doi: 10.1111/jcmm.13560

30. Eltzschig HK, Carmeliet P. Hypoxia and inflammation. N Engl J Med. (2011) 364:656-65. doi: 10.1056/NEJMra0910283

31. Ni C, Ma P, Wang R, Lou X, Liu X, Qin Y, et al. Doxorubicininduced cardiotoxicity involves IFN $\gamma$-mediated metabolic reprogramming in cardiomyocytes. J Pathol. (2019) 247:320-32. doi: 10.1002/path.5192

32. Violi F, Calvieri C, Cangemi R. Effect of corticosteroids on myocardial injury among patients hospitalized for community-acquired pneumonia: rationale and study design. The colosseum trial. Intern Emerg Med. (2020) 15:7986. doi: 10.1007/s11739-019-02117-0

33. Mumoli N, Cei M, Mazzone A, Conte G. Cardiac injury as prognostic value in COVID-19: more remains to be clarified. Intern Emerg Med. (2021) 16:267-8. doi: 10.1007/s11739-020-02540-8

34. Olsson T, Terent A, Lind L. Rapid emergency medicine score: a new prognostic tool for in-hospital mortality in nonsurgical emergency department patients. J Intern Med. (2004) 255:57987. doi: 10.1111/j.1365-2796.2004.01321.x

35. Grein J, Ohmagari N, Shin D, Diaz G, Asperges E, Castagna A, et al. Compassionate use of remdesivir for patients with severe COVID-19. N Engl J Med. (2020) 382:2327-36. doi: 10.1056/NEJMc20 15312

36. Wiersinga WJ, Rhodes A, Cheng AC, Peacock SJ, Prescott HC. Pathophysiology, transmission, diagnosis, and treatment of coronavirus disease 2019 (COVID-19): a review. JAMA. (2020) 324:782-93. doi: 10.1001/jama.2020.12839

37. Robbiani DF, Gaebler C, Muecksch F, Lorenzi JCC, Wang Z, Cho A, et al. Convergent antibody responses to SARS-CoV-2 in convalescent individuals. Nature. (2020) 584:437-42. doi: 10.1038/s41586-02 0-2456-9

Conflict of Interest: The authors declare that the research was conducted in the absence of any commercial or financial relationships that could be construed as a potential conflict of interest.

Copyright (c) 2021 Sun, Zhang, Wu, Wang, Xie, Zhang, Yuan, Zhang, Cui, Li, Zhang, Li, Wang, Yang, Lv, Zhang, Haines, Wu and Xie. This is an open-access article distributed under the terms of the Creative Commons Attribution License (CC $B Y)$. The use, distribution or reproduction in other forums is permitted, provided the original author(s) and the copyright owner(s) are credited and that the original publication in this journal is cited, in accordance with accepted academic practice. No use, distribution or reproduction is permitted which does not comply with these terms. 